\title{
Educação Geográfica, Movimentos Sociais e Território: formação de estudantes reflexivos
}

\author{
Geographic Education, Social Movements and Territory: Formation of Reflective \\ Students
}

\author{
Educación Geográfica, Movimientos Sociales y Territorios: Formación de \\ Estudiantes Reflexivos
}

Caio Bragueto da Mata ${ }^{1}$

\begin{abstract}
RESUMO: O presente texto é resultado de uma oficina pedagógica aplicada em três turmas do ensino médio de um colégio estadual de Londrina, PR. Teve como objetivo discutir o tema movimentos sociais e a categoria território na disciplina de geografia. Como procedimentos metodológicos foram utilizados leitura e fichamento de texto, planejamento e aplicação da oficina e, por último, análise e discussão dos resultados. Apesar das adversidades, os/as estudantes demonstraram estar aptos a entender, participar e criar um movimento que faça reivindicações pertinentes à melhoria das condições de vida dos coletivos.
\end{abstract}

PALAVRAS-CHAVE: Ensino de Geografia. Movimentos sociais. Território.

ABSTRACT: The presented paper is the result of a workshop applied to three different school classes in a state school in Londrina/pr. The purpose was to discuss social movements and the territory as a category subject. The methodology consisted on reading and annotating, on planning and applying the workshop and on analyzing and discussion the results. Besides the claims improvement for the life conditions of the whole.

KEYWORDS: Teaching Geography. Social movements. Territory.

RESUMEN: El presente texto es el resultado de un taller pedagógico aplicado en tres grupos de la enseñanza media de un colegio estadual de Londrina, PR. E tuvo como objetivo discutir el tema de los movimientos sociales y la categoría territorial en la disciplina de geografía. Como procedimientos metodológicos se utilizaron lectura y fichamiento de texto, planificación y aplicación del taller y, por último, análisis y discusión de los resultados. A pesar de las adversidades, los / las estudiantes demostraron ser aptos para entender, participar y crear un movimiento que haga reivindicaciones pertinentes a la mejora de las condiciones de vida de los colectivos.

PALABRAS CLAVES: Enseñanza de Geografía. Movimientos sociales. Territorio.

\footnotetext{
${ }^{1}$ Geografia - Universidade Estadual de Londrina - Rodovia Celso Garcia Cid/PR. 445 Km 380 Londrina-PR, e-mail cbragueto@hotmail.com.
} 


\section{INTRODUÇÃO}

O presente texto tem o objetivo discutir os movimentos sociais e a categoria território na disciplina de geografia. Sabe-se que muitos movimentos sociais têm o território como objeto de luta, e o vêem como uma necessidade e um direito de todos.

Para colocar em prática as ideias de discutir os movimentos sociais e o conceito de território na educação geográfica, planejou-se uma oficina pedagógica, que foi aplicada no Colégio Estadual Doutor Willie Davids, no município de Londrina, Paraná, e os resultados serão analisados e discutidos neste texto. Para sua construção, foram utilizados como procedimentos metodológicos: leitura e fichamento de texto, planejamento e aplicação da oficina pedagógica, análise e discussão dos resultados obtidos.

Após a aplicação da oficina, chegou-se à conclusão de que é de extrema relevância demonstrar aos/às estudantes como os movimentos sociais se articulam e transformam suas reivindicações em conquistas para que, dessa forma, talvez esses mesmos/as alunos/as, futuramente, lutem por melhorias, seja por uma educação de qualidade ou em busca de garantia dos direitos das classes populares.

\section{MOVIMENTOS SOCIAIS: BREVE DISCUSSÃO}

É de extrema importância demonstrar a relevância que os movimentos sociais têm para a melhoria das condições de vida das classes populares, em especial às denominadas minorias. O termo minoria diz respeito a determinado grupo humano ou social que esteja em inferioridade numérica ou em situação de subordinação socioeconômica, política ou cultural em relação a outro grupo, que é majoritário ou dominante em uma dada sociedade. Uma minoria pode ser étnica, religiosa, linguística, de gênero, idade, condição física ou psíquica (CHAVES, 1971).

Portanto, aos atuais e/ou futuros/as professores/as torna-se pertinente apresentar as discussões desta temática em sala de aula, demonstrando para os/as estudantes como esses movimentos podem apresentar reivindicações capazes de transformar a sociedade e, talvez, torná-la mais justa. No sentido de corroborar tais afirmações, Gohn (1991, p. 9) destaca: 
Os movimentos populares são quantitativamente os mais numerosos e ao meu ver, do ponto de vista político, os que têm gerados transformações sociais substantivas, dado o conteúdo de suas demandas, as relações que mantêm com o Estado e o papel que desempenham na luta de classes mais geral.

Vendramini e Machado (2011) apontam que movimentos sociais são coletivos que normalmente envolvem uma minoria de pessoas em busca de direitos ou que contemplam alguma reivindicação; é importantíssimo que eles se façam presentes na educação, para que esta possa ser de igual qualidade para todos, independentemente da sua classe social, cor, etnia e gênero.

Observa-se, através da afirmação dos autores, que os movimentos sociais exercem elevadíssima importância de cunho político e são capazes de produzir mudanças para pessoas que, muitas vezes, são excluídas de condições de uma vida digna na sociedade. Para demonstrar que, socialmente, os movimentos sociais exercem várias funções cruciais, Vendramini e Machado (2011), utilizando como exemplo as ações do Movimento Sem Terra (MST), escrevem que, ao se conscientizarem em relação às ações do capital que os agride, os/as trabalhadores/as tornar-se-iam mais conscientes; dessa forma, eles/as procurariam construir estratégias de enfrentamento e contraposição à lógica do capital, propondo a estruturação de um novo modelo de sociedade, pautado em outra concepção e outra forma de organização de trabalho e de vida.

É importante destacar que não é somente o MST que propaga ideias de cunho político, em tom de denúncia do alijamento histórico dos direitos envolvendo a educação. "No Brasil, com a redemocratização, foi possível observar esforços mais acentuados envidados pelos movimentos negros em trazer para a arena pública os problemas da discriminação racial" (SPOSITO, 2000, p. 75).

Portanto, para que uma sociedade se torne mais justa e equitativa e todos os sujeitos sociais tenham os mesmos direitos, é necessário que um coletivo ou algum grupo represente esses sujeitos e faça perceber as relações de hierarquia e poder desiguais presentes na sociedade (DAGNINO, 1994). Nesse sentido, os movimentos sociais aparecem como coletivos organizados com o intuito de empoderar diversos sujeitos, seja ele camponês, negro, mulher, indígena ou LGBT, dentre outros.

O "empoderamento" da comunidade [...]. Trata-se de processos que tenham a capacidade de gerar processos de desenvolvimento auto-sustentável, com a mediação de agentes externos - os novos educadores sociais atores fundamentais na organização e o desenvolvimento dos projetos. (GOHN, 2004, p. 12). 
Apesar de não tão explícita, a afirmação de Gohn demonstra que a união de um coletivo, independente de ações externas a ele, é fundamental principalmente para o empoderamento das classes populares no Brasil, muitas vezes sendo um dos principais responsáveis por conscientizar uma determinada comunidade e fazê-la mais presente no cotidiano político, educacional e econômico.

Mediante as diversas afirmações de autores que se dedicaram a estudar, conhecer e revelar a importância dos movimentos sociais para a sociedade é possível notar que abordálos no contexto educacional é de extrema relevância.

\section{DISCUSSÃO DO TERRITÓRIO NA GEOGRAFIA}

Ao trabalhar com movimentos sociais, é imprescindível falar em território, principalmente no âmbito da ciência geográfica. Alguns elementos devem ser considerados para que o conceito território seja compreendido. Primeiro, o território é construído historicamente a partir das relações de poder e, portanto, automaticamente envolve a sociedade e o espaço geográfico. Segundo, o território pode possuir uma denominação mais subjetiva, que pode estar relacionada à consciência ou à identidade. Mas pode demonstrar, também, uma dimensão mais objetiva, caracterizada pela dominação e apropriação de um determinado espaço por instrumentos de ação política econômica (HAESBAERT, 2007).

Através do que propõe Haesbaert (2007), sabe-se que o território, sendo objeto de disputa, envolve muitas questões sociais, políticas e econômicas, que devem ser discutidas. A luta de alguns precisa ser contextualizada a partir desse conceito geográfico, porque é através da disputa pelo território que os direitos são conquistados, como os direitos básicos de moradia, à educação e de alimentação. Observa-se aí a relevância de dialogar sobre território e associá-lo aos movimentos sociais; portanto, defende-se sua inserção no currículo da educação geográfica.

Para Cavalcanti (1998), o conceito de território tem uma larga utilização na história da ciência, mormente na geografia política e geopolítica. Ele está relacionado à esfera das práticas sociais (HAESBAERT, 2003), ou seja, o ser humano, por meio de sua atuação, como a partir do trabalho produtivo, transforma o espaço geográfico, cria relações de poder e disputa território.

É importante ressaltar que todas essas discussões sobre território devem ser relacionadas com o surgimento e a motivação da existência dos movimentos sociais e, para muitos desses movimentos, a pauta da discussão envolve determinado espaço de disputa com diferentes interesses. 
Nota-se aí a relação existente entre a geografia e os movimentos sociais, tendo como possibilidade a discussão da realidade em que os/as estudantes vivem. Para isso, podem-se pautar as disputas por terra no Brasil e todas as consequências que isso gera. É muito importante que os/as alunos/as das escolas conheçam o poder de questionar, principalmente para reivindicar um ensino de melhor qualidade.

Segundo Cavalcanti (1998), é importante discutir o conceito de território nas escolas. Porém, ao trabalhar essa discussão, é imprescindível que, primeiro de tudo, seja feito o diagnóstico a respeito do que os/as alunos/as já sabem sobre o conceito; depois disso, a representação dada pelos/as estudantes deve ser confrontada com entendimentos teóricos, para que essas representações sejam compreendidas à luz das teorias. Além disso, na discussão sobre território, deve-se ampliar o conceito, para que ele possa ser entendido no âmbito das desigualdades e das lutas entre classes e visto como instrumento de uso e exibição de poder. Para evidenciar o fato de que a população é vítima do excesso e desequilíbrio do poder exercido, Rafesttin (1993, p. 41) destaca:

A população representada como "coleção de seres humanos" é um trunfo, um recurso para o Estado, para as empresas, as igrejas, os partidos, etc. Trunfo sobre o qual se busca a posse, a dominação, ou ainda o controle, de maneira a integrá-lo, sob diversas formas, em processos. Há aí uma ambivalência da população, que ao mesmo tempo é fonte das organizações e trunfo dessas mesmas organizações, em diversos graus e sob diversas formas.

Observa-se que, em todas as afirmações citadas, o território é construído a partir da luta de classes, e é por ele que, muitas vezes, ela se desenvolve. Segundo Cavalcanti (1998), o conceito de território não é compreendido ou analisado de forma crítica pela maioria dos/as estudantes, que geralmente o associam à geografia política clássica, enquanto professores/as levantam apontamentos mais críticos em relação à sua ocupação, delimitando fronteiras existentes. Porém não conseguem produzir um diálogo reflexivo com os/as alunos/as no sentido de empoderá-los na ampliação de uma consciência sobre o conceito.

A partir do que escreve a autora, é necessário trabalhar com as discussões sobre movimentos sociais e território na educação geográfica. Demonstrar aos/às estudantes que, na verdade, a concentração de terras é uma característica fundante do Estado Nação brasileiro e que, devido a isso, muitas pessoas sofrem por não terem seus direitos básicos atendidos. A tudo isso se atrela a falta de um território para que possam viver e plantar, usar para fins produtivos e para o bem coletivo. 


\section{DISCUSSÃO DOS RESULTADOS DA OFICINA PEDAGÓGICA}

A partir da leitura dos referenciais, foi possível perceber a importância de se trabalhar com estudantes das escolas básicas e produzir um diálogo acerca do que são movimentos sociais e de como eles podem estar relacionados ao seu cotidiano. Além disso, houve a tentativa de relacionar os movimentos sociais ao conceito de território e a alguns conteúdos discutidos em sala de aula pelo/a professor/a, para que os/as alunos/as entendessem a importância de se pensar no território e os motivos de disputa, inclusive na vida deles/as.

Sabendo que, na escola pública, o livro didático aborda o tema movimentos sociais, mas não de maneira tão ampla e, talvez, até de forma distorcida; é necessário mostrar aos/as estudantes que eles têm a capacidade de fazer reivindicações e de protestar, seja a favor de uma educação de qualidade ou para qualquer direito social que o Estado deve conceder.

Além disso, Resende (1986, p. 25) aponta que "[...] a escola pública é também um espaço muito importante de fornecimento de uma educação que atenda aos interesses das classes populares." Portanto, assim como a escola pública, os movimentos sociais são os que lutam para garantir os direitos básicos de quem não os tem assegurados, por isso também a importância de trabalhar o tema com os/as jovens.

Os/as estudantes ocupam um espaço na cidade; sendo assim, é pertinente demonstrar a relação entre conflitos sócio-espaciais e território. É dessa maneira que eles/as podem perceber que existem disparidades em relação à organização sócio-espacial de uma determinada cidade, conhecendo e, talvez, participando de movimentos sociais que denunciem a segregação espacial e que proponham a todos/as o direito à cidade; quem sabe, esses mesmos estudantes, no futuro, construam uma sociedade mais justa e equitativa.

A oficina pedagógica foi realizada no dia 30 de setembro de 2016, na Escola Estadual Doutor Willie Davids, com estudantes dos primeiro, segundo e terceiro anos do ensino médio do período noturno, na cidade de Londrina, no Paraná. Situado no bairro Vila Casoni, o colégio atende alunos/as que vivem em suas proximidades, em sua grande maioria pessoas das classes populares, como aponta o Projeto Político Pedagógico (COLÉGIO ESTADUAL WILLIE DAVIDS, 2010).

Primeiramente, iniciou-se a oficina com aula expositiva e dialogada, com a finalidade de questioná-los sobre o que entenderiam por território e movimentos sociais. Depois, entregamos uma folha de papel sulfite A4 e pedimos para que criassem um logo que representasse um movimento, seja para reivindicar ou apenas se expressar. O intuito era de 
que, na prática, demonstrassem se realmente compreenderam como os dois temas se entrelaçam e como podem ser relacionados à sua vivência.

Foi possível notar, por parte dos/as alunos/as, que apesar de algumas vezes o tema ter sido discutido em sala de aula, poucos sabiam o que era um movimento social, ou conseguiam citar algum. Dos lembrados pelos/as alunos/as, o único nome que surgiu foi o do MST.

É válido, também, dizer que a oficina foi aplicada em uma sexta-feira à noite, nas três primeiras aulas; dessa forma, em algumas salas, como a do terceiro ano, não havia um número elevado de estudantes para que se pudesse realizar uma discussão com mais abrangência. Quando a oficina teve início, estavam presentes apenas três alunos na sala de aula, número que, paulatinamente, foi aumentando.

Ao fazer o levantamento prévio a respeito do que os alunos/as entendiam por movimentos sociais e território, já era esperado que, talvez, fosse necessário conceituar ambos os termos. Entretanto, em duas das três salas em que foi aplicada a oficina a discussão se estendeu, pois alguns/as alunos/as realmente ficaram interessados em entender a questão de conflito entre as classes sociais, disputa por terras e por direitos. Porém, na outra sala, alguns/as alunos/as não estavam tão preocupados, ou não conseguiram realmente entender o que significa claramente ou o que representa para a sociedade um movimento social e de que maneira esse/a aluno/a poderia pensar na criação de um movimento.

Notório também foi que, apesar de serem movimentos de cunho reivindicativo, dos 12 logos que foram criados, três se destacam, pois são reivindicações que envolvem a disputa por um dado território. Como já foi abordado, talvez para alguns estudantes não tenha ficado claro qual é o papel de um movimento social. Portanto, dos 12, podemos apontar pelo menos seis que não envolviam disputa por um dado território, estavam mais ligados a protestos individuais; faltou a ideia de coletividade, de protestar em busca de um bem comum que atinja um grupo de uma determinada população.

O que também nos faz pensar sobre como é importante para os/as alunos/as relacionar o conteúdo trabalhado em sala de aula com o que eles vivem; essas reivindicações, esses protestos mostram, em alguns casos, que muitos têm interesse em aprender e construir conhecimentos, porém não têm o apoio necessário para isso.

Apesar de seis dos cartazes estarem voltados para reclamações e queixas, o que também faz parte de um movimento social, eles não envolveram a disputa de território especificamente. Dos outros seis, três deles mostram claramente que os/as alunos/as têm reivindicações de cunho social de um espaço estudantil, disputa por melhoria das condições de moradia, saúde e deveres básicos de seus bairros. Em um deles notamos a disputa por uma saúde pública que atinja a todos e que tenha qualidade. 
Dos movimentos criados, três foram destaque, pois são os que mais atingiram um dos objetivos da pesquisa, ou seja, os/as alunos/as deveriam entender a disputa por território, como os movimentos sociais participam dessa dinâmica e por que são importantes.

A partir disso, em relação ao contexto da disputa por território, como mostra a Figura 1, duas alunas criaram, juntas, união contra o assédio nas ruas. Nesse logo, elas fizeram reivindicações em relação ao assédio sofrido pelas mulheres todos os dias. O que vale destacar também é que, mesmo de maneira implícita, o cartaz envolve um conflito relacionado ao espaço, ao território; o próprio nome diz: "União contra o assédio nas ruas", ou seja, a rua, a cidade, são lugares onde existem os mais variados conflitos, às vezes, esses conflitos podem ser a disputa pelo espaço, ou apenas o respeito ao frequentar esse espaço.

Figura 1 - União contra o assédio nas ruas

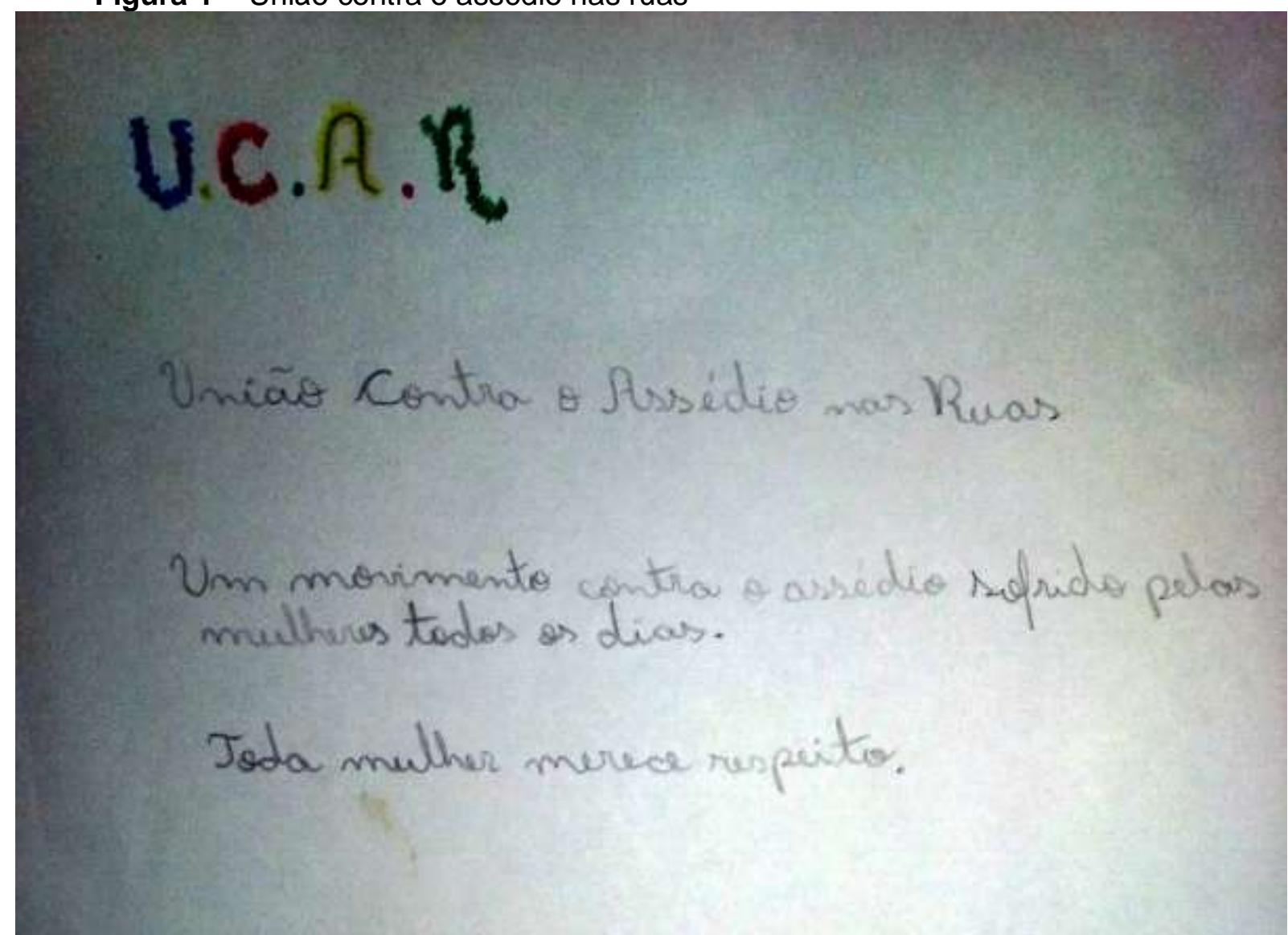

Autoria: alunos do Colégio Estadual Doutor Willie Davids, 2016.

O segundo movimento relaciona-se à ideia de pertencimento a um determinado lugar e à denúncia de opressão, como mostra a Figura 2. Em vez de falar sobre a precariedade do bairro, o aluno criou o movimento "Revolta nas Favelas", que retrata a opressão em relação às manifestações oriundas das classes populares. O aluno relata experiências vividas por ele, o cotidiano conflituoso do seu bairro, e demonstra a opressão que atinge os 
coletivos que ali vivem. Ressalta, também, a importância da união entre o povo, para que a justiça seja feita.

Figura 2 - Revolta nas favelas

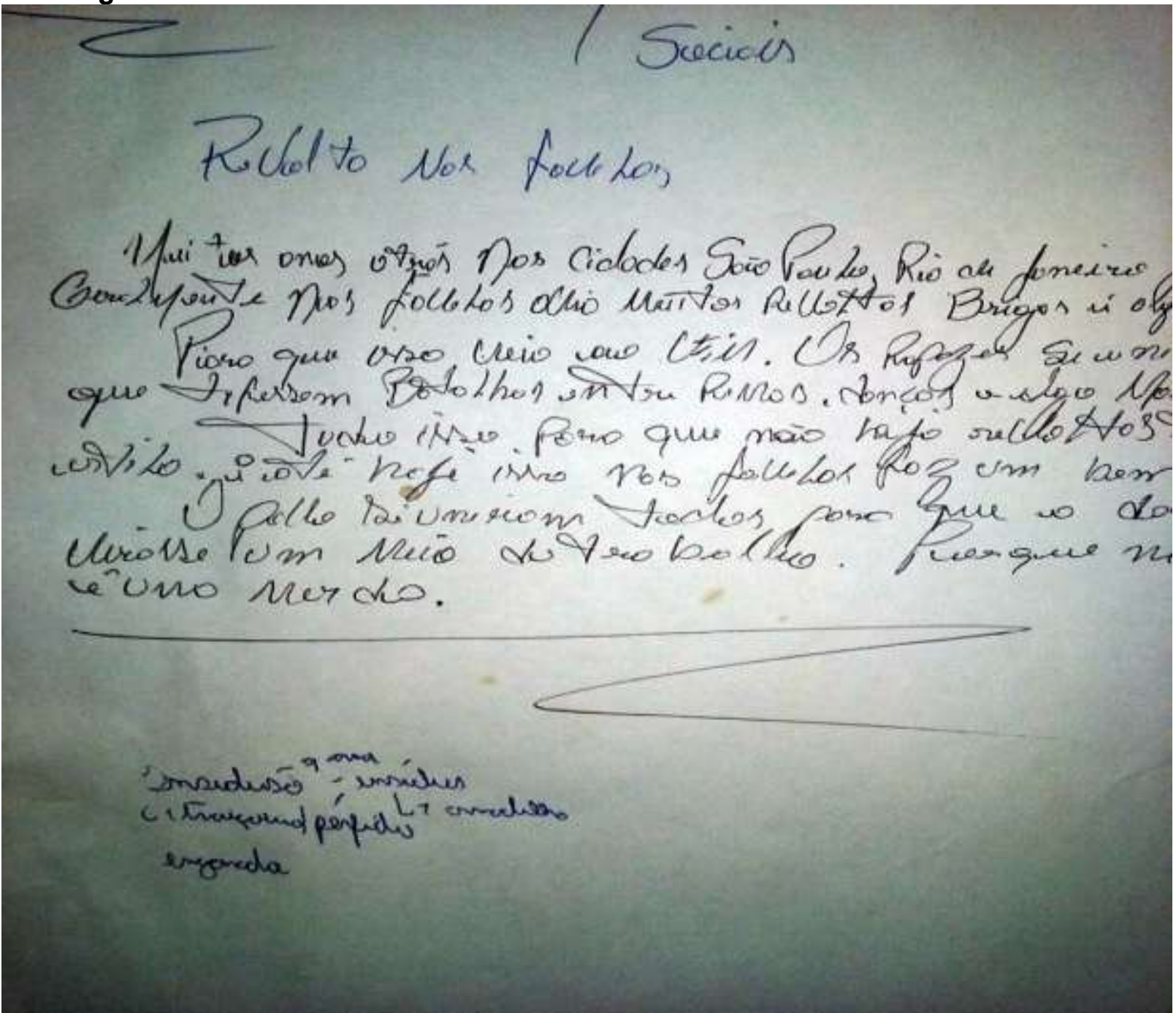

Autoria: alunos do Colégio Estadual Doutor Willie Davids, 2016.

E o terceiro logo retrata a disputa por um espaço estudantil de qualidade, através de uma contestação. A luta é por uma melhoria na educação, porém isso representa a disputa por um território. Assim como no primeiro logo, o movimento criado pelos/as alunos/as foi feito a partir de vivências no espaço escolar. A reivindicação nasce a partir de suas vivências, em determinado espaço, no caso o escolar; esses/as alunos/as querem ter boas aulas em escolas com uma estrutura adequada. Então, o grupo de estudantes criou o "Movimento Social Para a Educação", como se pode observar na Figura 3.

Observa-se, portanto que, muitos/as alunos/as entenderam o conteúdo discutido. De certo modo, o objetivo da oficina foi atingido, porque proporcionou aos/às professores/as 
uma maneira dinâmica para discutir os movimentos sociais na educação geográfica e relacioná-los com o território.

Figura 3 - Movimento Social para Educação

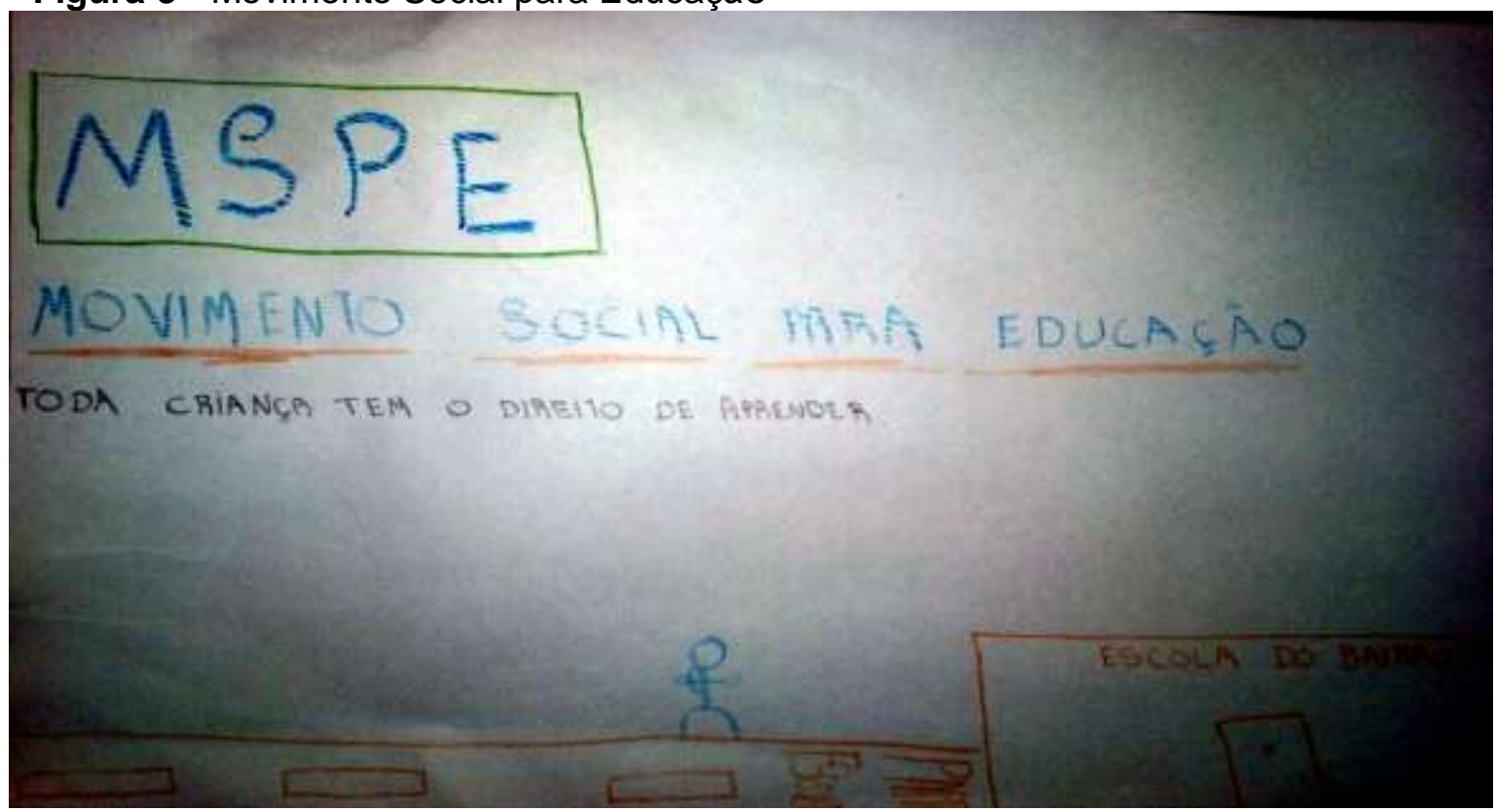

Autoria: alunos do Colégio Estadual Doutor Willie Davids, 2016.

Entende-se que as metas traçadas foram cumpridas, os/as alunos/as se empenharam e criaram vários movimentos com diferentes contestações. Algumas dificuldades existiram, pois, como são alunos/as que em geral trabalham, chegam à aula após um dia exaustivo e, se o conteúdo não for interessante para eles, é muito difícil fazer com que se concentrem. Pelo fato de discutir um conteúdo que, de certa forma, envolve o cotidiano deles, de todos nós, muitos tiveram vontade de saber sobre movimento social e sua relação com o território, e por que essas reivindicações existem, ou seja, foram instigados a pensar de forma crítica e reflexiva.

\section{CONSIDERAÇÕES FINAIS}

É importante realizar diálogos com os/as alunos/as das escolas básicas, independentemente do assunto, fazê-los interagir com os colegas e produzir o conhecimento. Trabalhar com movimentos sociais é exatamente aprimorar essa interação e a produção de conhecimentos próprios; além disso, demonstra a eles o poder do questionamento em busca de melhorias sociais e de uma educação de qualidade. Relacionar os movimentos aos conteúdos gerais da educação geográfica, como foi demonstrado na pesquisa, pode não ser tarefa fácil, porém é uma das bases para se entender a essência da luta desses coletivos. 
Com os resultados da pesquisa, notou-se que, muitos/as alunos/as não entendiam ou nem sabiam da existência de um movimento social. E, após verem o quão importante eles são para a sociedade, sentiram-se capazes de fazer reivindicações e de lutar por direitos. Tudo isso envolve a geografia, envolve a categoria território e, claro, os movimentos sociais.

Entende-se que o objetivo foi cumprido, os/as alunos/as se empenharam e criaram vários movimentos com várias contestações diferentes que, em alguns casos, estavam relacionados ao conceito da disputa por território.

\section{REFERÊNCIAS}

CAVALCANTI, L. S. Geografia, escola e construção de conhecimentos. Campinas: Papirus, 1998.

CHAVES, M. Minorias e seu estudo no Brasil. Revista de Ciências Sociais, Rio de Janeiro, v. 2 , n. 1, p. 149-168, 1971.

COLÉGIO ESTADUAL DR. WILLIE DAVIDS. Projeto político pedagógico. 2010.

Disponível em:

<http://www.Idawilliedavids.seed.pr.gov.br?reddeescola/escolas/18/1380/206/arquivos/File/P rojetoPoliticoPedagogico.pdf >. Acesso em: 24 jul. 2016.

DAGNINO, E. Movimentos sociais e a emergência de uma nova noção de cidadania. In: Política e sociedade no Brasil. São Paulo: Brasiliense, 1994. p. 103-115.

GOHN, M. G. Empoderamento e participação da comunidade em políticas sociais. Saúde e Sociedade, São Paulo, v. 13, n. 2, p. 20-31, maio/ago. 2004.

Movimentos sociais e luta por moradia. São Paulo: Loyola, 1991.

HAESBAERT, R. Da desterritorialização à multiterritorialidade. In: ENCONTRO NACIONAL DA ANPUR, 9., 2003, Rio de Janeiro. Anais... Porto Alegre: Associação Brasileira de Geógrafos, 2003. v. 3, p. 12-23.

O território em tempos de globalização. Revista Eletrônica de Ciências Sociais Aplicadas, Rio de Janeiro, v. 1, n. 2, p. 39-52, ago. 2007.

RAFFESTIN, C. Por uma geografia do poder. São Paulo: Ática, 1993.

RESENDE, M. S. A geografia do aluno trabalhador: caminhos para uma prática de ensino. São Paulo: Loyola, 1986.

SPOSITO, M. P. Algumas hipóteses sobre as relações entre movimentos sociais, juventude e educação. In: REUNUÃO ANUAL DA ANPED, 22., 1999, Caxambu. Anais... São Paulo: Universidade de São Paulo, 200. p. 73-94.

VENDRAMINI, C.; MACHADO, I. Escola e movimentos sociais: experiências em curso de campo brasileiro. São Paulo: Expressão Popular, 2011. 